\title{
Salivary proteins and microbiota as biomarkers for early childhood caries risk assessment
}

\author{
Abdullah S Hemadi, Ruijie Huang*, Yuan Zhou and Jing Zou \\ Early childhood caries (ECC) is a term used to describe dental caries in children aged 6 years or younger. Oral streptococci, such \\ as Streptococcus mutans and Streptococcus sorbrinus, are considered to be the main etiological agents of tooth decay in \\ children. Other bacteria, such as Prevotella spp. and Lactobacillus spp., and fungus, that is, Candida albicans, are related to the \\ development and progression of ECC. Biomolecules in saliva, mainly proteins, affect the survival of oral microorganisms by \\ multiple innate defensive mechanisms, thus modulating the oral microflora. Therefore, the protein composition of saliva can be a \\ sensitive indicator for dental health. Resistance or susceptibility to caries may be significantly correlated with alterations in \\ salivary protein components. Some oral microorganisms and saliva proteins may serve as useful biomarkers in predicting the risk \\ and prognosis of caries. Current research has generated abundant information that contributes to a better understanding of the \\ roles of microorganisms and salivary proteins in ECC occurrence and prevention. This review summarizes the microorganisms \\ that cause caries and tooth-protective salivary proteins with their potential as functional biomarkers for ECC risk assessment. The \\ identification of biomarkers for children at high risk of ECC is not only critical for early diagnosis but also important for \\ preventing and treating the disease. \\ International Journal of Oral Science Online publication 10 November 2017; e1; doi:10.1038/ijos.2017.35
}

Keywords: caries risk assessment; early childhood caries; salivary microorganisms; salivary proteins

\section{INTRODUCTION}

Dental caries are one of the most common chronic infectious diseases of preschool-aged children, characterized by the destruction of tooth tissues by synergistic complex effects among acids generated from the fermentation of dietary carbohydrates by bacteria and susceptible host factors, such as teeth and saliva. ${ }^{1}$ Tooth decay of primary teeth in children 71 months of age or younger is referred to as early childhood caries (ECC) and affects $23 \%$ of preschoolers in the USA and over $60 \%$ of children in China. ${ }^{2-3}$ Any sign of smooth-surface caries in children younger than 3 years of age is indicative of severe ECC (S-ECC). ${ }^{4}$ S-ECC is indicated by children from ages 3 through 5 years who have one or more cavitated missing teeth (due to caries), filled smooth surfaces in primary maxillary anterior teeth, or decayed, missing, or filled score of $\geq 4$ (age 3 years), $\geq 5$ (age 4 years), or $\geq 6$ (age 5 years) surfaces. ${ }^{4}$ Destruction of primary teeth has already occurred when ECC is present, which is not only harmful to a child's physical health but also has psychological and emotional effects. ${ }^{5}$ Thus, the preventive intervention of and early diagnosis of ECC are of particular clinical importance. Recent studies have focused on the assessment of risk factors and oral defense mechanisms in preventing ECC. We used the PubMed, EMBASE, Medline and OVID databases to search for related keywords to outline recent advances.

Many studies have correlated mutans streptococci with ECC. ${ }^{6-8}$ A systematic review by Parisotto et al. ${ }^{8}$ found that the count of salivary mutans streptococci is a strong risk indicator for ECC. Vachirarojpisan et al. ${ }^{9}$ noticed that the mutans streptococci level in unstimulated saliva was a statistically significant indicator of ECC, with an odds ratio $(\mathrm{OR})=4.5 ; 95 \%$ confidence interval $(\mathrm{CI})$ : 1.8-11.7. A correlation between lactobacilli and caries increment was also found in young children (3-4 years of age), with an $\mathrm{OR}=16.2$; 95\% CI: $1.12-233.36,{ }^{10}$ as well as a relative risk $=2.70 ; 95 \% \mathrm{CI}$ : $2.23-2.99 .{ }^{11}$ In addition to mutans streptococci and lactobacilli, Candida spp. is frequently present in the oral cavity of children with ECC. ${ }^{12-13}$

Saliva is a complex body fluid composed of organic and inorganic constituents that are essential for the health of the oral cavity. Saliva mainly originates from three pairs of major salivary glands, that is, parotid glands, submandibular and sublingual glands, and from numerous minor salivary glands situated in the oral submucosa. ${ }^{14}$ In addition to inevitable mixing with gingival crevicular fluid, saliva also contains desquamated cells of the oral epithelium, microorganisms, bronchial expectoration remains and food debris. ${ }^{15}$ Saliva

State Key Laboratory of Oral Diseases \& National Clinical Research Center for Oral Diseases \& Department of Pediatric Dentistry, West China Hospital of Stomatology, Sichuan University, Chengdu, China

*These authors contributed equally to this work.

Correspondence: Professor J Zou, State Key Laboratory of Oral Diseases \& National Clinical Research Center for Oral Diseases \& Department of Pediatric Dentistry, West China Hospital of Stomatology, No.14, 3rd Section, Renmin South Road, Chengdu 610041, China.

E-mail: zoujing1970@126.com

Accepted 1 August 2017 
principally consists of $99.5 \%$ water, $0.3 \%$ proteins and $0.2 \%$ trace and inorganic substances. ${ }^{16}$ Saliva is one of the innate defense systems of the human body that protects teeth by several mechanisms, such as improving tooth enamel by remineralization, neutralizing low plaque $\mathrm{pH}$, rinsing food debris, microorganisms and sugar aggregation, and by its antibacterial and bacterial properties. ${ }^{17-18}$ The concentration of proteins and polypeptides present in saliva is important in the maintenance of oral health and homeostasis, as increased frequency and severity of oral disease are often associated with qualitative and quantitative changes of the saliva proteome. ${ }^{19-20}$ Proteomic molecules, such as histatins, mucin, lactoperoxidase, defensins, proline-rich peptides and lactoferrin (LF) regulate the microbial flora of the oral cavity by exerting direct antibacterial effects. ${ }^{21-22}$ Many of the proteins present in saliva are critical for the protection of oral tissues against fungal or viral infections. ${ }^{23}$ Therefore, salivary protein composition may play an important role in the etiology of oral disease prevalence and dental caries development. ${ }^{21}$ Saliva collection and storage is easy, non-invasive, relatively inexpensive and is low risk for both the patient and medical staff. These characteristics of saliva are advantageous when studying caries biomarkers in infants, children and adults. In recent studies, saliva was used to evaluate the incidence of caries by examining bacterial abundance, protein identity and concentration, and buffer capacity within the saliva samples.

The physiological states of the human body can be examined by monitoring changes in the composition of saliva. ${ }^{21,24-25}$ The changes in salivary protein composition with aging were significantly correlated with dental caries prevalence. ${ }^{26}$ Saliva secretion and concentration differs depending on age and gender. ${ }^{27}$ The differences in total protein concentration of human whole saliva varies among different ages groups, as salivary protein concentration increases with increasing age. $^{28}$ Changes in saliva production with aging are correlated with higher caries risk and may be an index of caries incidence. ${ }^{29}$ In a longitudinal study, salivary concentrations of alpha-defensins 1-3, cathelicidins LL-37, LF, calprotectin and salivary immunoglobulin A (IgA) in 1-year-old children were measured at baseline. The concentrations of the same salivary components were measured in the same children at 3 years of age. The results showed increased concentrations of antimicrobial peptides (AMPs), IgA and Streptococcus mutans over time. $^{30}$

This review aims to summarize the following: (1) whether salivary microbes can be utilized as biomarkers for ECC risk assessment, (2) the influence of salivary proteins on oral microorganisms and caries occurrence and (3) whether salivary proteins can be used as biomarkers to predict ECC susceptibility and outcomes.

\section{MICROORGANISMS AS A RISK FACTOR FOR ECC}

\section{Mutans streptococci and lactobacilli}

Dental caries is the most common chronic infectious oral disease among children and teenagers in the world. Without early prevention, this infectious disease can lead to destruction of dental hard tissue and, eventually, tooth loss. A group of cariogenic bacteria, particularly mutant streptococci, S. mutans and Streptococcus sobrinus, are the species most frequently associated with tooth decay in children. ${ }^{31-32}$ Mutans streptococci are particularly cariogenic because of their aciduric and acidogenic properties and their ability to produce intracellular and extracellular polysaccharides that facilitate bacterial attachment on the tooth surface. Many studies have demonstrated a significant correlation between high caries prevalence in preschool children and a higher mutans streptococci and lactobacilli load in saliva or plaque. ${ }^{6,83-41}$ A systemic review provided by Thenisch et al. ${ }^{42}$ discussed the correlation between salivary mutans streptococci and ECC. The group found that the presence of mutans streptococci in the saliva of preschool children without caries is associated with considerably increased caries. ${ }^{42}$ It has been observed in studies that measured the mutans streptococci counts in saliva (4 reports; a total of 451 children) that the pooled risk ratio of caries was $2.11 ; 95 \%$ CI: 1.47-3.02. A longitudinal study that followed 39 children from the age of 2 years to the age of 4 years determined that the timing of colonization may impact the severity of disease. If colonization of $S$. mutans occurred at 2 years of age, the caries index values of decayed, missing and filled teeth $(\mathrm{dmft})$ were higher $(\mathrm{dmft}=10.6 \pm 5.3)$ at the age of 4 years than if children were colonized after the age of 2 years. ${ }^{43}$ By contrast, some studies have reported no significant association between ECC in multivariate regression or high levels of mutans streptococci in saliva. ${ }^{7,44}$ The lack of association between the salivary bacterial level and ECC incidence may be due to increased localized bacterial adherence to the tooth surface. Nevertheless, as the majority of studies support a positive correlation between salivary levels of mutans streptococci and ECC, mutans streptococci could serve as a marker for ECC onset. In addition to mutans streptococci, lactobacilli play a role in the progression of caries. ${ }^{31}$ Lactobacillus spp. play a role in caries progression through the production of water-insoluble polysaccharides that promote bacterial attachment to the tooth surface and to other bacteria, fill the gaps between bacteria, facilitate plaque accumulation and the retention of bacteria on the tooth surface, and confine organic acids that alter the microenvironment to enrich the aciduric microflora. ${ }^{45}$ Although lactobacilli play a significant role in the prognosis of dental caries, it is unlikely that they play any significant role in the inception of dental caries. ${ }^{46}$ Therefore, salivary lactobacilli counts could be indirectly related to caries progression.

\section{Candida species}

The Candida species of fungus asymptomatically colonizes the oral cavity together with other opportunistic pathogens. Depending on the oral and systemic conditions, these microorganisms in the mouth may shift from commensal to pathogenic microorganisms. Candida species are frequently detected in the oral cavity of children with ECC. ${ }^{13}$ Candida albicans invade the dentinal tubules and secrete acids promoting enamel demineralization. This fungus possesses the ability to adhere to the hydroxyapatite (HAP) substrates and dissolve HAP crystals by releasing calcium ions. Thus, C. albicans is a relevant pathogen in caries progression. Several reports have described the implication of Candida spp. in ECC and S-ECC. ${ }^{12-13,47-51}$ C. albicans can tolerate high acidic environments and produce high levels of organic acids, mainly acetic acid and pyruvic acid, ${ }^{52}$ which are more efficient in decreasing the $\mathrm{pH}$ of the milieu than the $S$. mutans secreted lactic acid. Some studies did not find a strong association between Candida spp. in saliva and caries levels in children with ECC. ${ }^{53}$ This does not diminish the potential for salivary C. albicans counts as a risk predictor for ECC.

\section{Other microorganisms}

In addition to oral streptococci and Candida spp., other oral microbial species have been associated with ECC, such as Biofidobacteria spp., Actinomyces spp., Veillonella spp. and Prevotella spp. ${ }^{54-55}$ As the composition of the microbiome may predict health or disease states, it is not surprising that the oral microbiota of children with S-ECC differs significantly from that of their caries-free counterparts. ${ }^{56-57}$ Several studies demonstrated that Prevotella spp., Actinomyces spp., Veillonella Porphyromonas, Selenomonas spp. and an unnamed Bifidobacterium species were associated with ECC. ${ }^{12,57-58}$ Tanner et al. ${ }^{55}$ found an increased prevalence of Prevotella spp. in S-ECC $(n=53)$ 
compared with caries-free $(n=32)$ children using microarray analysis. Ling et al. ${ }^{59}$ included 60 children with and without caries (3-6 year olds) in their study and analyzed the salivary microbiome using highthroughput barcoded pyrosequencing and PCR-denaturing gradient gel electrophoresis. They observed that the detection of salivary Prevotella spp. was higher in caries-active children compared with caries-free children. Another study characterized the diversity of microbial flora in the saliva of children (3-4 years old) with and without caries and found that Prevotella salivae was more prevalent in the caries-affected group than in the caries-free group $(P<0.05) .{ }^{38}$ As the abundance of Prevotella spp. differentiated caries-active subjects from healthy individuals, its prevalence may indicate a predictive role in the onset of dental caries. In a different study, "Microbial Indicators of Caries" was used to diagnose and predict the onset of caries over the course of 2 years in preschoolers who were clinically considered healthy. The accuracy of this prediction method and of the microbiota is similar, supporting the use of the Prevotella spp. for the timely prediction of caries. ${ }^{60}$ Hence, salivary Prevotella spp. may possibly be considered a predictor of ECC.

\section{SALIVARY PROTEINS AS A PROTECTIVE FACTOR FOR ECC}

Saliva is a significant factor in the development of dental caries. ${ }^{61}$ Saliva protects the tooth against loss of calcium and phosphate ions from the enamel by forming a dental pellicle. The salivary pellicle acts as a protective barrier and aids in preventing demineralization, promoting remineralization, keeping the oral cavity $\mathrm{pH}$ neutral and cleaning tooth surfaces by washing away residual food. ${ }^{62}$ The development of caries is influenced by the physiochemical properties of saliva, such as $\mathrm{pH}$, salivary flow rate, buffering capacity, varying protein concentrations and other components of saliva. Saliva contains many innate defense molecules that participate in the protection of oral tissues by either direct antimicrobial effect or interference with microbial colonization. These molecules include AMPs (cathelicidin peptide LL-37, alpha-defensins, beta-defensins, histatins and statherin), major salivary glycoproteins (mucins, proline-rich proteins (PRPs) and immunoglobulins) and minor salivary glycoproteins (agglutinin, LF, cystatins and lysozyme). These proteins play specific functional roles in the first line of defense of the oral cavity.

\section{Antimicrobial peptides}

AMPs are essential components of innate immunity, providing the first line of defense against oral microbial colonization and infection. ${ }^{63}$ Most AMPs have antimicrobial activity against Gram-negative and Gram-positive bacteria, ${ }^{63}$ fungi ${ }^{64}$ and viruses. ${ }^{65}$ AMPs are classified based on amino-acid composition, conformational structure and size. ${ }^{66}$ The most common AMPs expressed in the saliva are listed in Table 1 and described below.

Cathelicidin peptide LL-37. Cathelicidins are antimicrobial host defense peptides. The $18-\mathrm{kDa}$ cationic alpha-helical peptide, LL-37, is found in neutrophils and inflamed epithelia, as well as in saliva. ${ }^{67}$ The antibacterial effect of LL-37 and its derivatives is based on their cationic property. These molecules aggregate on microbial membranes to form ion channels and transmembrane pores to ultimately cause membrane leakage and membrane rupture. ${ }^{63}$ In a longitudinal study, 57 toddlers ( 12 to 24 months old) were followed for 2-3 years. The study showed a positive correlation between elevated concentrations of salivary LL-37 $(r=0.336, P<0.05)$ and higher numbers of $S$. mutans. ${ }^{30}$ This result suggests that increases in the concentration of salivary LL-37 may be a response to higher bacterial colonization. This report contradicts another study in which no correlation was found between LL-37 and mutans streptococci levels. ${ }^{74}$ Indeed, some reports suggest that the concentrations of salivary LL-37 in ECC have a weak or no positive correlation with dental caries. ${ }^{74-75}$ Davidopoulou et al. ${ }^{76}$ found that the concentration of LL-37 was lower in children with high caries activity in the primary dentition compared with caries-free children. Therefore, it is possible that LL-37 is an important innate immunity factor in the oral cavity, playing a protective role against caries. The relationship between salivary LL-37 and ECC is still unclear.

Defensins. The most prominent mammalian AMPs are the defensins. Defensins are typically peptides that are 29-35 amino acids in length, antimicrobial (prototype) cations and low in molecular weight (4-5 kDa). Depending on the pattern of cysteine pairing, two types of defensins are recognized, namely, the $\alpha$-defensins and the $\beta$-defensins. ${ }^{77}$ In in vitro studies, both $\alpha$-defensins and $\beta$-defensins exhibit non-specific antimicrobial activity against Gram-negative bacteria, Gram-positive bacteria and C. albicans. ${ }^{78-79}$ Ribeiro et al. ${ }^{75}$ examined salivary peptide profiles in 10- to 71-month-old children with and without ECC. The presence of $\alpha$-defensins- 3 and $\beta$-defensin3 reduced the incidence of ECC. However, a different study using enzyme-linked immunosorbent assay (ELISA) showed no significant differences between $\alpha$-defensins 1-3 salivary levels in 3-5-year-old children $(P=0.06)$ and caries severity. ${ }^{80}$ Malcolm et al. ${ }^{30}$ found that higher numbers of total plaque bacteria in 3-year-old children was positively correlated with the concentration of salivary $\alpha$-defensins $1-3$ $(r=0.412, P<0.01)$, suggesting a local host reaction to ECC. In one report, the salivary concentrations of human $\beta$-defensin- 2 and human $\beta$-defensin-3 in children between 36 and 60 months showed no correlation with ECC. ${ }^{74}$ By contrast, another study of 82 pediatric patients showed a significant increase in the concentration of $\beta$-defensin-2 $(2.29 \pm 0.05) \mathrm{ng} \cdot \mathrm{mL}^{-1}$ in the ECC group compared with the caries-free group $(2.15 \pm 0.07) \mathrm{ng} \cdot \mathrm{mL}^{-1.81}$ The high salivary concentration of $\beta$-defensin- 2 in caries-active subjects suggests that $\beta$-defensin-2 may contribute to caries susceptibility and can potentially be utilized to perform caries risk assessments in children. There have been relatively few studies assessing the relationship between salivary defensins and their usage as biomarkers for caries risk prediction for

Table 1 The most common AMPs expressed in saliva

\begin{tabular}{|c|c|c|c|}
\hline Salivary components & Main functions & Sources & Reference \\
\hline Cathelcidin LL3 & Antimicrobial activity & Salivary glands and duct, neutrophil leukocytes and gingival sulcus & $67-68$ \\
\hline Histatins & Antifungal and antibacterial & Parotid and submandibular salivary duct cells & $69-70$ \\
\hline Alpha-defensinvHNP1-3 & Microbicidal activity antiviral activity & Neutrophil granulocytes & 68,71 \\
\hline Beta-defensins hBD1 hBD2 hBD-3 & Microbicidal activity and antiviral properties & Mucosal cells & $68,71-72$ \\
\hline Statherin & Remineralization of enamel & Major and minor salivary glands & 73 \\
\hline
\end{tabular}


ECC; therefore, we cannot consider it as a caries risk prediction tool for ECC.

Histatins. Histatins are small cationic peptides consisting of at least 12 histidine-rich basic peptides, characterized by their histidine-rich structures ranging in size from 7 to 38 amino acids. ${ }^{82}$ The most common forms of the histidine-rich peptides are histatin 1, histatin 3 and histatin 5, with 38, 32 and 24 amino-acid residues, respectively. These three forms account for $\sim 85 \%$ of the total histatin proteins in saliva. ${ }^{83}$ Histatins, especially histatin 1 , may play a role in reducing bacterial colonization on tooth surfaces because it has the ability to incorporate into the acquired pellicle and block the binding site of bacteria on tooth surfaces. ${ }^{84-85}$ In an in vitro study, histatin 1 reduced S. mutans adhesion onto HAP surfaces by inhibiting the adsorption of salivary high-molecular-weight glycoproteins. ${ }^{85}$ In a study following 106 children (10-71 months old), there was no significant association between salivary histatin 3 and ECC. ${ }^{75}$ In a more recent study, the salivary peptides of children with S-ECC were assessed at different time periods, mainly before treatment, 1 week and 4 weeks after treatment. ${ }^{86}$ Utilizing magnetic bead-based matrix-assisted laser desorption/ionization time-of-flight mass spectrometry and western blotting, the results showed that salivary histatin 1 was expressed more in children with S-ECC 4 weeks after the treatment compared with before the treatment $(P<0.01)$. In one report, the level of histatin 5 in children's saliva had no association with ECC. ${ }^{74}$ Another group demonstrated a significant increase in the concentration of salivary histatin 5 in children with ECC $(n=41$ average age $=(5 \pm 2.3)$ years $)$ in comparison with the control group $(n=41$ average age $=(5 \pm 1.5)$ years). ${ }^{81}$ The most recent longitudinal study, published by Ao et al. ${ }^{87}$ found that increased histatin peptide in the saliva correlates with increased ECC incidence. Because of the available evidence of correlation between histatin concentration and ECC, salivary histatins may be considered to increase caries risk in young children.

Statherin. Statherin is a low-molecular-weight $(5.4 \mathrm{kDa})$ acidic protein composed of 43 amino acids. Statherin has various functions, including binding to HAP, inhibiting the spontaneous precipitation of calcium and phosphate salts from the supersaturated saliva, and inhibiting HAP crystal growth. Statherin has been suggested as a potential precursor of the acquired pellicle because it has a strong affinity to HAP. Maintaining saliva supersaturated with calcium phosphate salts is achieved by statherin, which enhances enamel remineralization, thereby maintaining the integrity of the tooth and inhibiting caries progression. ${ }^{88}$ Statherin reduces bacterial and fungal colonization by aggregating the microbes. This clumping process reduces the ability of bacteria to adhere to intraoral hard and soft tissue surfaces. ${ }^{88}$ Shimotoyodome et al..$^{85}$ found that statherin reduces S. mutans adhesion to HAP. Vitorino et al. ${ }^{89}$ reported a strong correlation between high levels of statherin and the absence of dental caries in children. This finding implies a protective role of statherin against caries. So far, no study has proved any association between statherin and ECC. Therefore, additional studies should be performed to further support the hypothesis that statherin can be used for caries risk prediction in ECC.

\section{Salivary glycoproteins}

The salivary glycoproteins are a wide range of structurally and functionally composite molecules of the saliva contributing to the formation of the salivary pellicle, which influences the pattern of microbial colonization and serves as the first line of defense in the oral cavity. These glycoproteins serve as primary nutrients for the resident oral microorganisms. Two forms of glycoproteins are present in the saliva, major salivary glycoproteins (Table 2) and minor salivary glycoproteins (Table 3).

Major salivary glycoproteins. Mucins: The mucin family consists of two predominant forms in human saliva, the high-molecular-weight mucins (MG1), with molecular weights above $1000 \mathrm{kDa}$, and the lowmolecular-weight mucins (MG2), with molecular weights from $150-200 \mathrm{kDa}$. Mucins found in human saliva protect teeth from demineralization induced by the acid produced from microbial metabolism. ${ }^{97}$ The acquired enamel pellicle is composed primarily of MG1, which serves as an attachment site for bacteria, as well as a permeable barrier for organic acid challenge and may aid bacterial colonization on oral surfaces. ${ }^{97}$ Many studies have reported that MG2 can interact with oral microorganisms by promoting their agglutination. ${ }^{90-91}$ Thus, MG2 may be an important antimicrobial agent. Levine et al..$^{98}$ reported that salivary mucins agglutinated S. mutans and S. sanguis. ${ }^{98}$ In a study conducted on 120 children with and without caries, which included preschool level (aged between 4 and 6 years old, $n=60$ ) and school level (aged between 9 and 11 years old, $n=60$ ) children, the salivary mucins levels were measured

Table 2 The most common major salivary glycoproteins expressed in saliva

\begin{tabular}{llc}
\hline Salivary components & Main functions & Sources \\
\hline MUC5B (mucin MG1) & Barrier protection and lubrication & Sublingual gland \\
MUC7 (mucin MG2) & Agglutination of microorganisms & Submandibular and labial glands \\
Proline-rich proteins & Remineralization of enamel & Parotid and submandibular glands \\
Immunoglobulins & Microbial binding; immune response & Major and minor salivary glands \\
\hline
\end{tabular}

Table 3 The most common minor salivary glycoproteins expressed in saliva

\begin{tabular}{|c|c|c|c|}
\hline Salivary components & Main functions & Sources & Reference \\
\hline Agglutinin & Antibacterial activity, aggregation of bacteria & Parotid, submandibular and sublingual glands & 94 \\
\hline Lactoferrin & Antimicrobial activity & Salivary glands, mucosal epithelial cells and neutrophil granulocytes & 68,72 \\
\hline Cystatins & Protease inhibitor & Submandibular gland, parotid gland and gingival crevicular & $93,95-96$ \\
\hline Lysozyme & Antibacterial, cell wall lysis & Salivary glands, neutrophil granulocytes and gingival crevicular fluid & 68,72 \\
\hline
\end{tabular}


using ELISA. The study reported no significant correlation between salivary mucin levels (MUC5B and MUC7) and ECC. In school children, they observed a negative correlation between salivary MUC5B and the number of decayed teeth in mixed dentition. ${ }^{99-100}$ The association between salivary mucins and dental caries may be affected by changes in the oral environment from primary to permanent dentition. There is still insufficient scientific evidence supporting the correlation between salivary mucins and ECC; thus, we cannot conclude that mucins are good indicators for predicting ECC risks.

Proline-rich proteins: Human salivary PRPs are composed of heterogeneous molecules, which are abundant in saliva, and mainly divided into the following three groups: basic PRP (bPRP), acidic PRPs (aPRP) and glycosylated PRPs. ${ }^{69}$ The aPRPs play a role in the formation of the acquired dental pellicle and promote the adhesion of S. mutans on HAP surfaces. ${ }^{84,101}$ aPRPs are important in maintaining a supersaturation of calcium ions in relation to ionic phosphate in saliva. Thus, the aPRPs may be a natural substance in preserving the calcium homeostasis of saliva. ${ }^{97}$ Furthermore, aPRPs play a significant role in the protection of tooth surfaces by regulating the precipitation of calcium phosphate onto dental enamel. ${ }^{102}$ A report by Ribeiro et al. ${ }^{75}$ identified the molecular masses of saliva from children with and without ECC $(n=106)$ and concluded that the presence of proline-rich peptides (in particular, IB-4) significantly increased the chance of caries $(P=0.035)$. Supporting this idea, a study by Bhalla et al. ${ }^{99}$ showed that a higher number of PRP bands were observed in the saliva of subjects with ECC. The majority of studies support the correlation between elevated PRP levels and the increased incidence of ECC, thereby indicating the potential use of PRPs as predictors for the prognosis of ECC.

Immunoglobulins: In addition to AMPs in the oral cavity, human saliva contains several immunoglobulins. Salivary immunoglobulins compose $\sim 5 \%-15 \%$ of whole salivary proteins. ${ }^{21}$ IgA is the major subclass of salivary immunoglobulins $(50 \%-60 \%)$ found in the saliva, and the rest belong to the IgG and IgM subclass. Salivary immunoglobulins are mucosal antibodies that act as the first line of defense, and they include two major antibodies, namely, secretory $\operatorname{IgA}(\operatorname{sg} A)$ and IgG. ${ }^{103}$ Salivary IgA constitutes $60 \%$ of the immunoglobulin in the saliva. IgA scan neutralize bacterial toxins and enzymes, interfere with the adherence of the bacteria to the tooth surface by physically blocking bacterial adhesions, inhibiting bacterial metabolism, reducing the hydrophobicity of bacteria and aggregating or clumping the bacteria together, which aids in the antibacterial action of the saliva. ${ }^{21,104}$ Controversy remains in the field regarding the relationship between salivary immunoglobulin and dental caries. According to a systemic review and meta-analysis, the literature shows an association between elevated levels of salivary IgA and increased caries activity in subjects. ${ }^{105}$ Indeed, many studies have reported significantly higher levels of salivary IgA in children with ECC potentially pointing to sIgA as a protective mechanism against cariogenic bacteria, especially $S$. mutans. ${ }^{10,37,61,106-111}$ In a longitudinal study conducted by Alaluusua, ${ }^{112}$ the salivary IgA value increased rapidly from $0.021 \mathrm{~g} \cdot \mathrm{L}^{-1}$ $(\log$ mean $1.68 \pm 0.33)$ to $0.052 \mathrm{~g} \cdot \mathrm{L}^{-1}(\log$ mean $1.28 \pm 0.24)$ in children from age 1 to 2 years. After 2 years of age, the level of salivary IgA remained constant, although the caries-active group had a significantly higher level of IgA compared with those of the caries-free group. ${ }^{12}$ The high concentration of salivary immunoglobulin in children with ECC may be associated with an increased antigenic load, leading to the high production of antibodies. On the other hand, one study reported an inverse relationship between salivary IgA level and caries experience in 453 - to 6-year-old children, ${ }^{113}$ while another report did not observe any correlation between IgA concentration and caries activity among children aged 3-6 years. ${ }^{114}$ However, most studies provided evidence of higher IgA levels in children with ECC and suggest its likelihood as a caries biomarker. Salivary IgG plays a protective role in the oral cavity by inhibiting $S$. mutans growth, adherence and acid production. ${ }^{115}$ A cross-sectional study $(n=90)$ shows that the concentration of salivary IgG was significantly higher among children with ECC $(P<0.05) .{ }^{107}$ Another study supports a correlation between higher levels of total salivary IgG and ECC prevalence, whereas the total IgM level was similar in children with and without ECC. ${ }^{106}$ Increased production of antibodies is linked to antigenic load; hence, it is unsurprising that there are increased concentrations of salivary immunoglobulins in children with ECC. Owing to the association between ECC and increased concentrations of salivary IgA and IgG, it may be useful to use these molecules as caries risk biomarkers.

Minor salivary glycoproteins. Agglutinin: Salivary agglutinin (SAG) is a high-molecular-mass $(\sim 340 \mathrm{kDa})$ component of human saliva. SAG was originally characterized as an $S$. mutans agglutinating glycoprotein. ${ }^{116}$ SAG is highly glycosylated and extremely sticky, potentially binding to the pellicle and interacting with unattached bacteria, resulting in the aggregation of bacteria that are more easily swallowed or flushed away. ${ }^{93,117-118}$ Thus, SAG plays a role in the oral clearance of bacteria. Some studies have reported a correlation between increased levels of agglutinin in saliva and increased numbers of $S$. mutans in dental plaque and susceptibility to dental caries. ${ }^{119}$ Saliva-mediated aggregation and adherence plays a direct role in caries resistance. Caries-resistant individuals show a two-fold enhancement of saliva-mediated aggregation compared with that of the cariessusceptible group. ${ }^{120}$ However, owing to the lack of convincing evidence in the literature, SAG cannot yet be used as predictor for ECC incidence.

Lactoferrin: LF is an iron-binding cationic glycoprotein with a molecular weight of $\sim 80 \mathrm{kDa}$. LF possesses potent activity against S. mutans, fungi, parasites and viruses. ${ }^{121} \mathrm{LF}$ has the ability to bind and kill bacteria via direct interactions through the strongly basic $\mathrm{N}$-terminal region of the glycoprotein that consists of 47 amino acids. ${ }^{122}$ In addition, LF and other cationic peptides are capable of neutralizing the interaction between bacterial lipopolysaccharides (LPS) and host defense cells. ${ }^{123}$ This interaction can alter the permeability of the outer membrane of Gram-negative bacteria and release LPS. ${ }^{124}$ Because of its antimicrobial activity, salivary LF is thought to play a major role in caries susceptibility. A study investigating the efficacy of toothpaste containing LF, lactoperoxidase and lysozyme found that it was capable of reducing the salivary colony forming-units of S. mutans and Lactobacillus acidophilus in children with S-ECC. ${ }^{125}$ In an in vitro study, the killing of S. mutans by human LF is dose-dependent. ${ }^{126}$ These studies suggest that LF protects against $S$. mutans colonization and can therefore be used in dental caries prevention. Another study, focusing on children $(n=42$, age range from 36 to 71 months), reported that the concentration of LF was higher in caries-free individuals than in ECC individuals. This study also found that lower concentrations of unstimulated salivary LF might have a positive relationship with ECC and may therefore be used as a predictive factor for ECC. ${ }^{127}$ Supporting this claim, Hao et al. ${ }^{128}$ detected higher concentrations of LF in high $\mathrm{dmft}$ children than in caries-free children, which may be related to caries prevention in primary dentition. ${ }^{128}$ However, the relationship between salivary LF and ECC is unclear. Therefore, salivary LF cannot be used as a caries risk indicator in ECC. 
Cystatins: Cystatins belongs to a heterogeneous family of proteins with a conserved consensus sequence in their active site. Cystatins are cysteine proteinase inhibitors, antimicrobial and immunomodulatory and are present in all mucosal secretions. Cystatins have been found to bind to HAP and may therefore play an important role in the acquired dental pellicle formation, as well as a role in the enamel remineralization process. ${ }^{70,84,95}$ Moreover, higher quantities of cystatins SN and cystatin $S$ in samples from caries-free individuals suggest that inhibition of proteolytic events on salivary proteins might indirectly provide tooth protection. ${ }^{129}$ At this time, it is not possible to use the cystatin level to determine the risk for ECC.

Lysozyme: Lysozyme is an antibacterial enzyme found in high amounts in body fluids such as saliva, serum, tears and amniotic fluid, as well as in low amounts in bile, urine and cerebrospinal fluid. Lysozyme promotes bacterial clearance through aggregation and adherence. Furthermore, it has the ability to destroy and inhibit bacterial growth. ${ }^{88,130}$ In an in vitro study, S. mutans and L. casei were inhibited by lysozyme. ${ }^{131}$ A study conducted by Moslemi et al. ${ }^{127}$ examined 42 children (aged 36-71 months) and demonstrated a statistically significant increase in the salivary lysozyme level in cariesfree children $\left(9573.81 \mathrm{ng} \cdot \mathrm{ml}^{-1}\right.$ ) compared with ECC children $\left(2180 \mathrm{ng} \cdot \mathrm{mL}^{-1}\right) .{ }^{127}$ Others have reported significantly higher concentrations of lysozyme in unstimulated and stimulated saliva in children with S-ECC compared with caries-free children. ${ }^{108,132}$ The higher level of lysozyme in the S-ECC group than in the caries-free group might be due to a compensatory mechanism. In specific situations, in the presence of caries or high levels of $S$. mutans, the secretion of lysozyme, which represents a protective mechanism, may be stimulated. ${ }^{127}$ However, a different study has shown no significant relationship between lysozyme concentration and caries in children. ${ }^{128}$ Evidence that supports the relationship between lysozyme and ECC is not strong. Therefore, lysozyme cannot be used as a predictive factor for ECC incidence.

\section{Total salivary proteins}

Several studies have investigated the relationship between the concentration of total salivary proteins and dental caries. A systemic review study conducted by Martins et al. ${ }^{133}$ reported no consistent correlation between salivary proteins and dental caries in terms of protein phenotypes, protein molecular weight or the concentration of total proteins. A recent review shows that the association between many salivary factors and dental caries has yet to be fully elucidated. ${ }^{134}$ Hao et al. ${ }^{128}$ reported higher levels of total salivary proteins in a cariesfree group $\left((1032.44 \pm 221.99) \mathrm{mg} \cdot \mathrm{L}^{-1}, P<0.001\right)$ compared with a $\mathrm{dmft}$ group $(852.02 \pm 206.14) \mathrm{mg} \cdot \mathrm{L}^{-1}$, suggesting an effective protective function of salivary proteins. Other studies demonstrated that the concentration of proteins was increased with caries activity in children. ${ }^{135-136}$ Several other investigations did not observe a statistically significant difference in the total salivary protein concentration between children with and without ECC. ${ }^{106}$ It is possible that the lack of association between salivary proteins and dental caries is due to the different levels of structure and function redundancies found in saliva. The relation between dental caries in children with ECC and total salivary protein concentration is not well established. Further studies are required to ascertain the value of total salivary protein concentration as a caries risk predictor in young children.

\section{CONCLUSION}

The retrieved studies show a highly significant correlation between higher caries prevalence in preschool children with higher levels of microbials, such as mutans streptococci, C. albicans and Prevotella spp., and salivary proteins, including IgA, IgG immunoglobulins, PRP and histatin peptides, in saliva compared with caries-free individuals. Therefore, based on the results of these studies, these saliva components may be used as biomarkers for ECC. To date, other salivary protein components have no association (no clear association has been found between other salivary proteins and ECC risks) with caries risk prediction, and the amount of total salivary proteinsis found not to be useful in predicting caries risk.

\section{ACKNOWLEDGEMENTS}

This work was supported by the National Natural Science Foundation of China 81400502 (Qiong Zhang), and the Young Teacher Research Start Funding of Sichuan University 2016SCU11049 (Yuan Zhou). We thank Prof Zhang Ping and Dr Hussein Helal for their contributions to this work, with special thanks to Prof Hui Wu and Stephanie Garcia at UAB in the United States for their comments on this paper.

1 Selwitz RH, Ismail AI, Pitts NB. Dental caries. Lancet 2007; 369(9555): 51-59.

2 Dye BA, Hsu KL, Afful J. Prevalence and measurement of dental caries in young children. Pediatr Dent 2015; 37(3): 200-216.

3 Hu DY, Hong X, Li X. Oral health in China-trends and challenges. Int J Oral Sci 2011; 3(1): 7-12.

4 Colak H, Dulgergil CT, Dalli M et al. Early childhood caries update: a review of causes, diagnoses, and treatments. J Nat Sci Biol Med 2013; 4(1): 29-38.

5 Losso EM, Tavares MC, Silva JY et al. Severe early childhood caries: an integral approach. J Pediatr 2009; 85(4): 295-300.

6 Fan $\mathrm{C}$, Wang W, Xu T et al. Risk factors of early childhood caries among children in Beijing: a case-control study. BMC Oral Health 2016; 16(1): 98.

7 Seki M, Karakama F, Terajima T et al. Evaluation of mutans streptococci in plaque and saliva: correlation with caries development in preschool children. J Dent 2003; 31(4): 283-290.

8 Parisotto TM, Steiner-Oliveira C, Silva CM et al. Early childhood caries and mutans streptococci: a systematic review. Oral Health Prev Dent 2010; 8(1): 59-70.

9 Vachirarojpisan T, Shinada K, Kawaguchi $Y$ et al. Early childhood caries in children aged 6-19 months. Community Dent Oral Epidemiol 2004; 32(2): 133-142.

10 Parisotto TM, King WF, Duque C et al. Immunological and microbiologic changes during caries development in young children. Caries Res 2011; 45(4): 377-385.

11 Gao X, Hsu CY, Loh T et al. Role of microbiological factors in predicting early childhood caries. Pediatr Dent 2014; 36(4): 348-354.

12 Lozano Moraga CP, Rodriguez Martinez GA, Lefimil Puente CA et al. Prevalence of Candida albicans and carriage of Candida non-albicans in the saliva of preschool children, according to their caries status. Acta Odontol Scand 2017; 75(1): 30-35.

13 de Carvalho FG, Silva DS, Hebling J et al. Presence of mutans streptococci and Candida spp. in dental plaque/dentine of carious teeth and early childhood caries. Arch Oral Biol 2006; 51(11): 1024-1028.

14 Lawrence HP. Salivary markers of systemic disease: noninvasive diagnosis of disease and monitoring of general health. J Can Dent Assoc 2002; 68(3): 170-174.

15 Kaufman E, Lamster IB. The diagnostic applications of saliva-a review. Crit Rev Oral Biol Med 2002; 13(2): 197-212.

16 Chiappin S, Antonelli G, Gatti R et al. Saliva specimen: a new laboratory tool for diagnostic and basic investigation. Clin Chim Acta 2007; 383(1-2): 30-40.

17 Hicks J, Garcia-Godoy F, Flaitz C. Biological factors in dental caries: role of saliva and dental plaque in the dynamic process of demineralization and remineralization (part 1). J Clin Pediatr Dent 2003; 28(1): 47-52.

18 Dawes C. Salivary flow patterns and the health of hard and soft oral tissues. J Am Dent Assoc 2008; 139(Suppl): 18S-24S.

19 Scarano E, Fiorita A, Picciotti PM et al. Proteomics of saliva: personal experience. Acta Otorhinolaryngol Ital 2010; 30(3): 125-130.

20 Dawes C, Pedersen AM, Villa $A$ et al. The functions of human saliva: a review sponsored by the World Workshop on Oral Medicine VI. Arch Oral Biol 2015; 60(6): 863-874.

21 Van Nieuw Amerongen A, Bolscher JG, Veerman EC. Salivary proteins: protective and diagnostic value in cariology? Caries Res 2004; 38(3): 247-253.

22 Schipper R, Loof A, de Groot J et al. SELDI-TOF-MS of saliva: methodology and pretreatment effects. J Chromatogr 2007; 847 (1):45-53.

23 Oppenheim FG, Salih E, Siqueira WL et al. Salivary proteome and its genetic polymorphisms. Ann NY Acad Sci 2007; 1098: 22-50.

24 de Almeida Pdel V, Gregio AM, Machado MA et al. Saliva composition and functions: a comprehensive review. J Contemp Dent Pract 2008; 9(3): 72-80.

25 Banderas-Tarabay JA, Zacarias-D'Oleire IG, Garduno-Estrada R et al. Electrophoretic analysis of whole saliva and prevalence of dental caries. A study in Mexican dental students. Arch Med Res 2002; 33(5): 499-505.

26 Mungia R, Cano SM, Johnson DA et al. Interaction of age and specific saliva component output on caries. Aging Clin Exp Res 2008; 20(6): 503-508. 
27 Inoue $\mathrm{H}$, Ono K, Masuda W et al. Gender difference in unstimulated whole saliva flow rate and salivary gland sizes. Arch Oral Biol 2006; 51(12): 1055-1060.

28 Sun $\mathrm{S}$, Zhao F, Wang $\mathrm{Q}$ et al. Analysis of age and gender associated $\mathrm{N}$-glycoproteome in human whole saliva. Clin Proteomics 2014; 11(1): 25.

29 Guo L, Shi W. Salivary biomarkers for caries risk assessment. J Calif Dent Assoc 2013; 41(2): 107-109, 112-118.

30 Malcolm J, Sherriff A, Lappin DF et al. Salivary antimicrobial proteins associate with age-related changes in streptococcal composition in dental plaque. Mol Oral Microbio 2014; 29(6): 284-293

31 Tanzer JM, Livingston J, Thompson AM. The microbiology of primary dental caries in humans. J Dent Educ 2001; 65(10): 1028-1037.

32 Nurelhuda NM, Al-Haroni M, Trovik TA et al. Caries experience and quantification of Streptococcus mutans and Streptococcus sobrinus in saliva of Sudanese schoolchildren. Caries Res 2010; 44(4): 402-407.

33 Edelstein BL, Ureles SD, Smaldone A. Very high salivary streptococcus mutans predicts caries progression in young children. Pediatr Dent 2016; 38(4): 325-330.

34 Pattanaporn K, Saraithong P, Khongkhunthian S et al. Mode of delivery, mutans streptococci colonization, and early childhood caries in three- to five-year-old Thai children. Community Dent Oral Epidemiol 2013; 41(3): 212-223.

35 Ghasempour M, Rajabnia R, Irannejad A et al. Frequency, biofilm formation and acid susceptibility of Streptococcus mutans and Streptococcus sobrinus in saliva of preschool children with different levels of caries activity. Dent Res J 2013; 10(4): 440-445.

$36 \mathrm{Ma} \mathrm{C}$, Chen $\mathrm{F}$, Zhang $\mathrm{Y}$ et al. Comparison of oral microbial profiles between children with severe early childhood caries and caries-free children using the human oral microbe identification microarray. PLoS One 2015; 10(3): e0122075.

37 Yang $\mathrm{Y}$, Li Y, Lin $\mathrm{Y}$ et al. Comparison of immunological and microbiological characteristics in children and the elderly with or without dental caries. Eur J Oral Sci 2015; 123(2): 80-87.

38 Jiang S, Gao X, Jin L et al. Salivary microbiome diversity in caries-free and cariesaffected children. Int J Mol Sci 2016; 17(12): 1-13.

39 Teanpaisan R, Thitasomakul S, Piwat S et al. Longitudinal study of the presence of mutans streptococci and lactobacilli in relation to dental caries development in 324 month old Thai children. Int Dent J 2007; 57(6): 445-451.

40 Law V, Seow WK. A longitudinal controlled study of factors associated with mutans streptococci infection and caries lesion initiation in children 21 to 72 months old. Pediatr Dent 2006; 28(1): 58-65.

41 Leong PM, Gussy MG, Barrow SY et al. A systematic review of risk factors during first year of life for early childhood caries. Int J Paediatr Dent 2013; 23(4): 235-250.

42 Thenisch NL, Bachmann LM, Imfeld T et al. Are mutans streptococci detected in preschool children a reliable predictive factor for dental caries risk? A systematic review. Caries Res 2006; 40(5): 366-374.

43 Alaluusua S, Renkonen OV. Streptococcus mutans establishment and dental caries experience in children from 2 to 4 years old. Scand J Dent Res 1983; 91(6): 453-457.

44 Olmez S, Uzamis M, Erdem G. Association between early childhood caries and clinical, microbiological, oral hygiene and dietary variables in rural Turkish children. Turkish J Pediatr 2003; 45(3): 231-236.

45 Hamada S, Slade HD. Biology, immunology, and cariogenicity of Streptococcus mutans. Microbiol Rev 1980; 44(2): 331-384.

46 Corby PM, Lyons-Weiler J, Bretz WA et al. Microbial risk indicators of early childhood caries. J Clin Microbiol 2005; 43(11): 5753-5759.

47 de Carvalho FG, Vieira BR, Santos RL et al. In vitro effects of nano-hydroxyapatite paste on initial enamel carious lesions. Pediatr Dent 2014; 36(3): 85-89.

48 Shen S, Samaranayake LP, Yip HK et al. Bacterial and yeast flora of root surface caries in elderly, ethnic Chinese. Oral Dis 2002; 8(4): 207-217.

49 Beighton D, Brailsford S, Samaranayake LP et al. A multi-country comparison of caries-associated microflora in demographically diverse children. Community Dent Health 2004; 21(1 Suppl): 96-101.

50 Radford JR, Ballantyne HM, Nugent $Z$ et al. Caries-associated micro-organisms in infants from different socio-economic backgrounds in Scotland. J Dent 2000; 28(5) 307-312.

51 Xiao J, Moon Y, Li L et al. Candida albicans carriage in children with severe early childhood caries (S-ECC) and maternal relatedness. PLoS One 2016; 11(10): e0164242.

52 Klinke T, Kneist S, de Soet JJ et al. Acid production by oral strains of Candida albicans and lactobacilli. Caries Res 2009; 43(2): 83-91.

53 Neves AB, Lobo LA, Pinto KC et al. Comparison between clinical aspects and salivary microbial profile of children with and without early childhood caries: a preliminary study. J Clin Pediatr Dent 2015; 39(3): 209-214.

54 Palmer CA, Kent Jr R, Loo CY et al. Diet and caries-associated bacteria in severe early childhood caries. J Dent Res 2010; 89(11): 1224-1229.

55 Tanner AC, Kent Jr RL, Holgerson PL et al. Microbiota of severe early childhood caries before and after therapy. J Dent Res 2011; 90(11): 1298-1305.

56 Beighton D. The complex oral microflora of high-risk individuals and groups and its role in the caries process. Community Dent Oral Epidemiol 2005; 33(4): 248-255.

57 Tanner AC, Mathney JM, Kent RL et al. Cultivable anaerobic microbiota of severe early childhood caries. J Clin Microbiol 2011; 49(4): 1464-1474.

58 Kanasi E, Johansson I, Lu SC et al. Microbial risk markers for childhood caries in pediatricians' offices. J Dent Res 2010; 89(4): 378-383.
59 Ling Z, Kong J, Jia P et al. Analysis of oral microbiota in children with dental caries by PCR-DGGE and barcoded pyrosequencing. Microbial Ecol 2010; 60(3): 677-690.

60 Teng F, Yang F, Huang S et al. Prediction of early childhood caries via spatial-temporal variations of oral microbiota. Cell Host Microbe 2015; 18(3): 296-306.

61 Thaweboon S, Thaweboon B, Nakornchai S et al. Salivary secretory lgA, pH, flow rates, mutans streptococci and Candida in children with rampant caries. Southeast Asian J Trop Med Public Health 2008; 39(5): 893-899.

62 Featherstone JD. The science and practice of caries prevention. J Am Dent Assoc 2000; 131(7): 887-899.

63 Brogden KA. Antimicrobial peptides: pore formers or metabolic inhibitors in bacteria? Nat Rev Microbiol 2005; 3(3): 238-250.

64 Aerts AM, Francois IE, Cammue BP et al. The mode of antifungal action of plant, insect and human defensins. Cell Mol Life Sci 2008; 65(13): 2069-2079.

65 Klotman ME, Chang TL. Defensins in innate antiviral immunity. Nat Rev Immunol 2006; 6(6): 447-456.

66 Harris F, Dennison SR, Phoenix DA. Anionic antimicrobial peptides from eukaryotic organisms. Curr Protein Pept Sci 2009; 10(6): 585-606.

67 Murakami M, Ohtake T, Dorschner RA et al. Cathelicidin antimicrobial peptides are expressed in salivary glands and saliva. J Dent Res 2002; 81(12): 845-850.

68 Gorr SU. Antimicrobial peptides of the oral cavity. Periodontology 2000 2009; 51: $152-180$.

69 de Sousa-Pereira P, Amado F, Abrantes J et al. An evolutionary perspective of mammal salivary peptide families: cystatins, histatins, statherin and PRPs. Arch Oral Biol 2013; 58(5): 451-458.

70 Lenander-Lumikari M, Loimaranta V. Saliva and dental caries. Adv Dent Res 2000; 14: 40-47.

71 White MR, Helmerhorst EJ, Ligtenberg A et al. Multiple components contribute to ability of saliva to inhibit influenza viruses. Oral Microbiol Immunol 2009; 24(1): 18-24.

72 Wiesner J, Vilcinskas A. Antimicrobial peptides: the ancient arm of the human immune system. Virulence 2010; 1(5): 440-464.

73 Xiao $Y$, Karttunen M, Jalkanen J et al. Hydroxyapatite growth inhibition effect of pellicle statherin peptides. J Dent Res 2015; 94(8): 1106-1112.

74 Colombo NH, Ribas LF, Pereira JA et al. Antimicrobial peptides in saliva of children with severe early childhood caries. Arch Oral Biol 2016; 69: 40-46.

75 Ribeiro TR, Dria KJ, de Carvalho CB et al. Salivary peptide profile and its association with early childhood caries. Int J Paediatr Dent 2013; 23(3): 225-234.

76 Davidopoulou S, Diza E, Menexes G et al. Salivary concentration of the antimicrobial peptide LL-37 in children. Arch Oral Biol 2012; 57(7): 865-869.

77 Yamasaki K, Gallo RL. Antimicrobial peptides in human skin disease. Eur J Dermatol 2008; 18(1): 11-21.

78 Abiko Y, Nishimura M, Kaku T. Defensins in saliva and the salivary glands. Med Electron Microsc 2003; 36(4): 247-252.

79 Dale BA, Fredericks LP. Antimicrobial peptides in the oral environment: expression and function in health and disease. Curr Issues Mol Biol 2005; 7(2): 119-133.

80 Toomarian L, Sattari M, Hashemi N et al. Comparison of neutrophil apoptosis, alphadefensins and calprotectin in children with and without severe early childhood caries. Iranian J Immunol 2011; 8(1): 11-19.

81 Jurczak A, Koscielniak D, Papiez M et al. A study on beta-defensin-2 and histatin- 5 as a diagnostic marker of early childhood caries progression. Biol Res 2015; 48: 61.

82 Johnson DA, Yeh CK, Dodds MW. Effect of donor age on the concentrations of histatins in human parotid and submandibular/sublingual saliva. Arch Oral Biol 2000; 45(9): 731-740.

83 Kavanagh K, Dowd S. Histatins: antimicrobial peptides with therapeutic potential. J Pharmacy Pharmacol 2004; 56(3): 285-289.

84 Vitorino R, Calheiros-Lobo MJ, Duarte JA et al. Peptide profile of human acquired enamel pellicle using MALDI tandem MS. J Sep Sci 2008; 31(3): 523-537.

85 Shimotoyodome A, Kobayashi $\mathrm{H}$, Tokimitsu I et al. Statherin and histatin 1 reduce parotid saliva-promoted Streptococcus mutans strain MT8148 adhesion to hydroxyapatite surfaces. Caries Res 2006; 40(5): 403-411.

86 Sun X, Huang X, Tan X et al. Salivary peptidome profiling for diagnosis of severe early childhood caries. J Transl Med 2016; 14(1): 240.

87 Ao S, Sun X, Shi X et al. Longitudinal investigation of salivary proteomic profiles in the development of early childhood caries. J Dent 2017; 61: 21-27.

88 Humphrey SP, Williamson RT. A review of saliva: normal composition, flow, and function. J Prosthet Dent 2001; 85(2): 162-169.

89 Vitorino R, Lobo MJ, Duarte JR et al. The role of salivary peptides in dental caries. Biomed Chromatogr 2005; 19(3): 214-222.

90 Koc Ozturk L, Yarat A, Akyuz S et al. Investigation of the $\mathrm{N}$-terminal coding region of MUC7 alterations in dentistry students with and without caries. Balkan J Med Genet 2016; 19(1): 71-76.

91 Sonesson M, Wickstrom C, Kinnby B et al. Mucins MUC5B and MUC7 in minor salivary gland secretion of children and adults. Arch Oral Biol 2008; 53(6): 523-527.

92 Satyanarayana J, Gururaja TL, Narasimhamurthy S et al. Synthesis and conformational features of human salivary mucin C-terminal derived peptide epitope carrying Thomsen-Friedenreich antigen: implications for its role in self-association. Biopolymers 2001; 58(5): 500-510.

93 Fabian TK, Hermann P, Beck A et al. Salivary defense proteins: their network and role in innate and acquired oral immunity. Int J Mol Sci 2012; 13(4): $4295-4320$ 
94 Edwards AM, Manetti AG, Falugi F et al. Scavenger receptor gp340 aggregates group A streptococci by binding pili. Mol Microbiol 2008; 68(6): 1378-1394.

95 Dickinson DP. Salivary (SD-type) cystatins: over one billion years in the making-but to what purpose? Crit Rev Oral Biol Med 2002; 13(6): 485-508.

96 Rudney JD, Staikov RK, Johnson JD. Potential biomarkers of human salivary function: a modified proteomic approach. Arch Oral Biol 2009; 54(1): 91-100.

97 Buzalaf MA, Hannas AR, Kato MT. Saliva and dental erosion. J Appl Oral Sci 2012; 20(5): 493-502.

98 Levine MJ, Herzberg MC, Levine MS et al. Specificity of salivary-bacterial interactions: role of terminal sialic acid residues in the interaction of salivary glycoproteins with Streptococcus sanguis and Streptococcus mutans. Infect Immun 1978; 19(1): 107-115.

99 Bhalla S, Tandon S, Satyamoorthy K. Salivary proteins and early childhood caries: a gel electrophoretic analysis. Contemp Clin Dent 2010; 1(1): 17-22.

100 Angwaravong 0, Pitiphat W, Bolscher JG et al. Evaluation of salivary mucins in children with deciduous and mixed dentition: comparative analysis between high and low caries-risk groups. Clin Oral Invest 2015; 19(8): 1931-1937.

101 Shimotoyodome A, Kobayashi H, Nakamura J et al. Reduction of saliva-promoted adhesion of Streptococcus mutans MT8148 and dental biofilm development by tragacanth gum and yeast-derived phosphomannan. Biofouling 2006; 22(3/4): 261-268.

102 Hay DI, Carlson ER, Schluckebier SK et al. Inhibition of calcium phosphate precipitation by human salivary acidic proline-rich proteins: structure-activity relationships. Calcif Tissue Int 1987; 40(3): 126-132.

103 Brandtzaeg P. Do salivary antibodies reliably reflect both mucosal and systemic immunity? Ann NY Acad Sci 2007; 1098: 288-311.

104 Russell MW, Hajishengallis G, Childers NK et al. Secretory immunity in defense against cariogenic mutans streptococci. Caries Res 1999; 33(1): 4-15.

105 Fidalgo TK, Freitas-Fernandes LB, Ammari M et al. The relationship between unspecific s-IgA and dental caries: a systematic review and meta-analysis. J Dent 2014; 42(11): 1372-1381.

106 de Farias DG, Bezerra AC. Salivary antibodies, amylase and protein from children with early childhood caries. Clin Oral Invest 2003; 7(3): 154-157.

107 Bagherian A, Jafarzadeh A, Rezaeian M et al. Comparison of the salivary immunoglobulin concentration levels between children with early childhood caries and caries-free children. Iran J Immunol 2008; 5(4): 217-221.

108 Bai J, Zhou Q, Bao ZY et al. Comparison of salivary proteins between children with early childhood caries and children without caries. Chin J Stomatol 2007; 42(1): 21-23.

109 Bagherian A, Asadikaram G. Comparison of some salivary characteristics between children with and without early childhood caries. Indian J Dent Res 2012; 23(5): 628-632.

110 Koga-lto CY, Martins CA, Balducci I et al. Correlation among mutans streptococci counts, dental caries, and IgA to Streptococcus mutans in saliva. Braz Oral Res 2004; 18(4): 350-355.

111 Al Amoudi N, Al Shukairy H, Hanno A. A comparative study of the secretory IgA immunoglobulins (s.IgA) in mothers and children with SECC versus a caries free group children and their mothers. J Clin Pediat Dent 2007; 32(1): 53-56.

112 Alaluusua S. Longitudinal study of salivary IgA in children from 1 to 4 years old with reference to dental caries. Scand J Dent Res 1983; 91(3): 163-168.

113 Omar OM, Khattab NM, Rashed LA. Glucosyltransferase B, immunoglobulin a, and caries experience among a group of Egyptian preschool children. J Dent Child (Chic) 2012; 79(2): 63-68.

114 Shifa S, Muthu MS, Amarlal D et al. Quantitative assessment of IgA levels in the unstimulated whole saliva of caries-free and caries-active children. J Indian Soc Pedodont Prev Dent 2008; 26(4): 158-161.

115 Gregory RL, Kindle JC, Hobbs LC et al. Function of anti-Streptococcus mutans antibodies: inhibition of virulence factors and enzyme neutralization. Oral Microbiol Immunol 1990; 5(4): 181-188.

116 Bikker FJ, Ligtenberg AJ, van der Wal JE et al. Immunohistochemical detection of salivary agglutinin/gp-340 in human parotid, submandibular, and labial salivary glands. J Dent Res 2002; 81(2): 134-139.

117 Prakobphol A, Xu F, Hoang VM et al. Salivary agglutinin, which binds Streptococcus mutans and Helicobacter pylori, is the lung scavenger receptor cysteine-rich protein gp-340. J Biol Chem 2000; 275(51): 39860-39866.
118 Carlen A, Bratt P, Stenudd C et al. Agglutinin and acidic proline-rich protein receptor patterns may modulate bacterial adherence and colonization on tooth surfaces. J Dent Res 1998; 77(1): 81-90.

119 Carlen A, Olsson J, Ramberg P. Saliva mediated adherence, aggregation and prevalence in dental plaque of Streptococcus mutans, Streptococcus sanguis and Actinomyces spp., in young and elderly humans. Arch Oral Biol 1996; 41(12): 1133-1140.

120 Rosan B, Appelbaum B, Golub E et al. Enhanced saliva-mediated bacterial aggregation and decreased bacterial adhesion in caries-resistant versus caries-susceptible individuals. Infect Immun 1982; 38(3): 1056-1059.

121 Fine DH, Toruner GA, Velliyagounder $\mathrm{K}$ et al. A lactotransferrin single nucleotide polymorphism demonstrates biological activity that can reduce susceptibility to caries. Infect Immun 2013; 81(5): 1596-1605.

122 Chapple DS, Hussain R, Joannou CL et al. Structure and association of human lactoferrin peptides with Escherichia coli lipopolysaccharide. Antimicrob Agents Chemother 2004; 48(6): 2190-2198.

123 Rosenfeld Y, Papo N, Shai Y. Endotoxin (lipopolysaccharide) neutralization by innate immunity host-defense peptides. Peptide properties and plausible modes of action. J Biol Chem 2006; 281(3): 1636-1643.

124 Ellison RT 3rd, Giehl TJ, LaForce FM. Damage of the outer membrane of enteric gramnegative bacteria by lactoferrin and transferrin. Infect Immun 1988; 56(11): 2774-2781.

125 Gudipaneni RK, Kumar RV, G J et al. Short term comparative evaluation of antimicrobial efficacy of tooth paste containing lactoferrin, lysozyme, lactoperoxidase in children with severe early childhood caries: a clinical study. J Clin Diagn Res 2014; 8(4): ZC18-ZC20.

126 Velusamy SK, Markowitz K, Fine DH et al. Human lactoferrin protects against Streptococcus mutans-induced caries in mice. Oral Dis 2016; 22(2): 148-154.

127 Moslemi M, Sattari M, Kooshki F et al. Relationship of salivary lactoferrin and lysozyme concentrations with early childhood caries. J Dent Res Dent Clin Dent Prospects 2015; 9(2): 109-114.

128 Hao GF, Lin HC. Relationship of concentration of lactoferrin and lysozyme in saliva and dental caries in primary dentition. Chin J Stomatol 2009; 44(2): 82-84.

129 Vitorino R, de Morais Guedes S, Ferreira R et al. Two-dimensional electrophoresis study of in vitro pellicle formation and dental caries susceptibility. Eur J Oral Sci 2006; 114(2): 147-153.

130 Ibrahim HR, Thomas U, Pellegrini A. A helix-loop-helix peptide at the upper lip of the active site cleft of lysozyme confers potent antimicrobial activity with membrane permeabilization action. J Biol Chem 2001; 276(47): 43767-43774.

131 de Andrade FB, de Oliveira JC, Yoshie MT et al. Antimicrobial activity and synergism of lactoferrin and lysozyme against cariogenic microorganisms. Braz Dent J 2014; 25(2): 165-169.

132 Lertsirivorakul J, Petsongkram B, Chaiyarit $\mathrm{P}$ et al. Salivary lysozyme in relation to dental caries among Thai preschoolers. J Clin Pediatr Dent 2015. 39(4): 343-347.

133 Martins C, Buczynski AK, Maia LC et al. Salivary proteins as a biomarker for dental caries-a systematic review. J Dent 2013; 41(1): 2-8.

134 Gao X, Jiang S, Koh D et al. Salivary biomarkers for dental caries. Periodontology 2000 2016; 70(1): 128-141.

135 Tulunoglu O, Demirtas S, Tulunoglu I. Total antioxidant levels of saliva in children related to caries, age, and gender. Int J Paediatr Dent 2006; 16(3): 186-191.

136 Preethi BP, Reshma D, Anand P. Evaluation of flow rate, pH, Buffering capacity, calcium, total proteins and total antioxidant capacity levels of saliva in caries free and caries active children: an in vivo study. Indian J Clin Biochem 2010; 25(4): 425-428

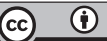

This work is licensed under a Creative Commons Attribution 4.0 International License. The images or other third party material in this article are included in the article's Creative Commons license, unless indicated otherwise in the credit line; if the material is not included under the Creative Commons license, users will need to obtain permission from the license holder to reproduce the material. To view a copy of this license, visit http://creativecommons.org/licenses/by/4.0/

(C) The Author(s) 2017 